\title{
Factor Analysis of the Perceptions of Prospective Teachers on Early Child Development (ECD) Functionaries
}

\author{
Evidence S. Matangi ${ }^{1, *}$,Adwell Mhlanga ${ }^{1}$, Phoebe Kashora ${ }^{2}$, Jenneth Musiyiwa ${ }^{3}$, Tendai Chakarisa ${ }^{4}$ \\ ${ }^{1}$ Department of Statistics, University of Zimbabwe, Harare, Zimbabwe \\ ${ }^{2}$ Department of Communication Skills, Women's University in Africa, Harare, Zimbabwe \\ ${ }^{3}$ Department of ECD, Women's University in Africa, Harare, Zimbabwe \\ ${ }^{4}$ Child Sensitive Social Policies Department, Women's University in Africa, Harare, Zimbabwe \\ *Corresponding author: evidence_matangi@yahoo.com
}

Received May 16, 2013; Revised November 19, 2013; Accepted December 23, 2013

\begin{abstract}
This research seeks to investigate perceptions of student teachers on nurseries and housemaids on Early Childhood Development (ECD). Six factors were extracted on nurseries and five were extracted for housemaids accounting for almost the same amount of variance. The main factor for nurseries functionary importance in ECD was stimulation of the mental and social emphasis of the children; and for housemaids it was on the moral development of the children and their complimentary role to nurseries. Housemaids were more paramount in ECD in terms of their ability to fill in for time-poor parents unlike nurseries due to the varying financial requirements, they were also more flexible on the space requirements for children's development. Overall, factor analysis was more pronounced for the perceptions on housemaids than nurseries on ECD, which suggest the presence of extraneous variables especially economic ones that influence more the latter's viability than the former.
\end{abstract}

Keywords: early child development, housemaids, linear combinations, nurseries, perception

Cite This Article: Evidence S. Matangi, Adwell Mhlanga, Phoebe Kashora, Jenneth Musiyiwa, and Tendai Chakarisa, "Factor Analysis of the Perceptions of Prospective Teachers on Early Child Development (ECD) Functionaries." American Journal of Applied Mathematics and Statistics 1, no. 6 (2013): 128-133. doi: 10.12691/ajams-1-6-4.

\section{Introduction}

Early childhood development (ECD) is a critical period in child development which starts from conception to age 8.This period is the foundation stage, not only of the child's education but also of adult's later physical, social, emotional, cognitive, and linguistic development. Research studies have revealed that years from 0-3 are critical for development, in the areas of socio-emotional, cognitive and linguistic skills. Thus the family plays a significant role in providing the natural environment for nurturing the development of the critical skills. Housemaid and nursery care is not the ideal environment for child development physically, cognitively, emotionally and linguistically. It is against this background that this paper seeks to analyze the factors that influence the perceptions of prospective teachers in early child development. These factors were drawn from a study on Perceptions on the Interplay of Housemaids and Nurseries on Early Child Development (ECD).

\section{Literature Review}

A nursery is a play activity and instruction based programme which does not provide child care necessarily for the poor parent. It provides care and education for young children, and supports children's survival, growth, development and learning including health, nutrition and hygiene, among others, from birth to entry into primary school. Nurseries according to [1] provide better development opportunities for the children, than in home care by the maid. Ideally, the services provided by a nursery are an extension of the function of the home and not a substitute for it [2]. Scientists have argued that the period between birth and eight years of age is crucial for the development of the foundations of physical, social, emotional and cognitive skills which develop in a simultaneous and inter-connected fashion. [3] further argues that high quality nurseries improve school readiness and later outcomes for young children. In a research which involved working women in Dubai, women stressed that they preferred high quality child care centers for the expertise they provided. On the other hand housemaids who take care of young children at home also render services that are an extension of the functions of the parents and not a substitute for parents. However, they lack knowledge and skills on providing stimulation and education for the children. They are limited in terms of child growth and development. 
At a nursery school, children's intellectual ability enhancement, social and general awareness development through peer interactions takes place. In other words, the holistic development of children is influenced positively at a nursery. This is true in that at a nursery, children's development is possible through play. [4] contend that play is an important experience for children. [5] added that emotional development is supported as children develop their self-esteem through play by becoming more skilled with regulation of affect and learning to identify emotional states of others. Play has the potential of strengthening empathy and sensitivity towards others through perspective taking. As children gain experience imagining what others are thinking and feeling, they become more skilled in expressing empathy and compassion towards others [6,7] view play as an integral component in learning and child development. In the domain of cognitive development, every day play in ECD often sets the foundation for early mathematical thinking as children experiment with shape, space, pattern and number found in their surroundings [8]. Play activities provide socioemotional benefits when children play together. Social play helps children learn to subordinate desires to social rules, cooperate with others willingly, and engage in socially appropriate behavior [9]. Fantasy play or makebelieve play has been found to be crucial for building children's social competence, including their ability to self-soothe and cope emotionally. Through play, children acquire knowledge and practice new skills, providing a foundation for more complex cognitive processes and academic success. With housemaids the total development of the child may not be possible. Housemaids lack the expertise, skills and knowledge on child stimulation and development. They could enhance all round development of children if they had the ability and skills to make suggestions, provide play opportunities and to organize materials and equipment.

Nurseries, to a large extent, develop children's personality and self reliance. They provide communal support intervention for mothers. [10] felt that children developed their self-esteem and confidence at a nursery school. The way children feel about themselves affects how they behave and how they relate to others and how successful they are in their learning. Personal, social and emotional development forms the foundation for successful relationships later in life. Children gain confidence and self-esteem once they become more independent and self-reliant. Children who are given opportunities to be self-reliant tend to develop a 'can-do' attitude [10].

However, the use of foreign language is rife in nurseries and yet language is a key factor in education. Language is in itself a living symbol of the community which links social and age barriers [11]. Linguistics and education psychologists agree that the use of the mother tongue as the language of instruction in the early years of education is advantageous especially where the development of cognitive faculties is concerned. In Zimbabwe, from nursery to grade three, the medium of instruction should be in the language that is commonly understood in the community of the child [12].

Housemaids, to a large extent, communicate with children in the language that the children understand. They also comfort children in their mother tongue. These memories make up a major part of their identity [11,13] noted that the Arabic language of information was now being eroded by English in spite of the Ministry of Education's prescribed regulation. This is also due to immigrant housemaids who do not speak Arabic to their children but use English as the medium of instruction. Recent studies also found the phenomenon of the China's adult children's dependency on their aging parents and this family set up has a positive impact on the child's emotional, linguistic and cultural development [14].

Generally, children are well disciplined at home rather than at nursery school. Experts discourage child care at a nursery school for children in the first year of life. [1] noted that there was a conviction among women that young children are better reared at home. Zimbabwe has early childhood development centre regulations which stipulate that no child may attend an ECD centre before s/he attains the age of three [15]. In China, mothers are able to maintain outside work due to the availability of grandparents to serve as an alternative child care because these mothers have a general mistrust of domestic helpers [14]. In Czechoslovakia, if a family can live on the father's income, the mother stays at home during the child's early years and at about three, the father's income, the mother stays at home during the child's early years and at about three, many children are sent to day nurseries. It is during this time that mothers are expected to instill social skills, cultural norms and values in children which are acceptable in the society. They are also expected to reprimand children when they display unacceptable behaviour. However, both housemaids and nurseries play a significant role in achieving social outcomes of a good health in children.

Optimum growth and development of the child are enhanced through play and for children to play, they need space. Children enjoy climbing, crawling, jumping and balancing either in natural environments or manufactured equipment such as climbing frames and tunnels among others. Physical play develops self confidence and competence in children. It also develops both fine and gross motor skills and it gives children more spatial awareness. Since this play involves other children, they develop skills of cooperation. It requires a lot of space for play. Many homes do not have large gardens with space to provide children with slides, swings or a large space for running around. This opportunity can be offered through nurseries [10].

\section{Materials and Methods}

A descriptive research design was used in this investigation and a secondary source of data [16] was used in this study. This consisted of a sample of 61 prospective early childhood teachers at the Women's University in Africa (WUA), which was purposively sampled. The sample consisted of 55 (90.25) females and 6 (9.8\%) males showing that this was a female-dominated profession.

Figure 1 shows that the $45.90 \%$ of the respondents were in the age group $40-49$ hence mature enough to comprehend the needs for effective ECD. The data revealed that $54(88.5 \%)$ respondents were themselves raised by both parents, $3(4.9 \%)$ by single parents and $4(6.6 \%)$ by grandparents. 


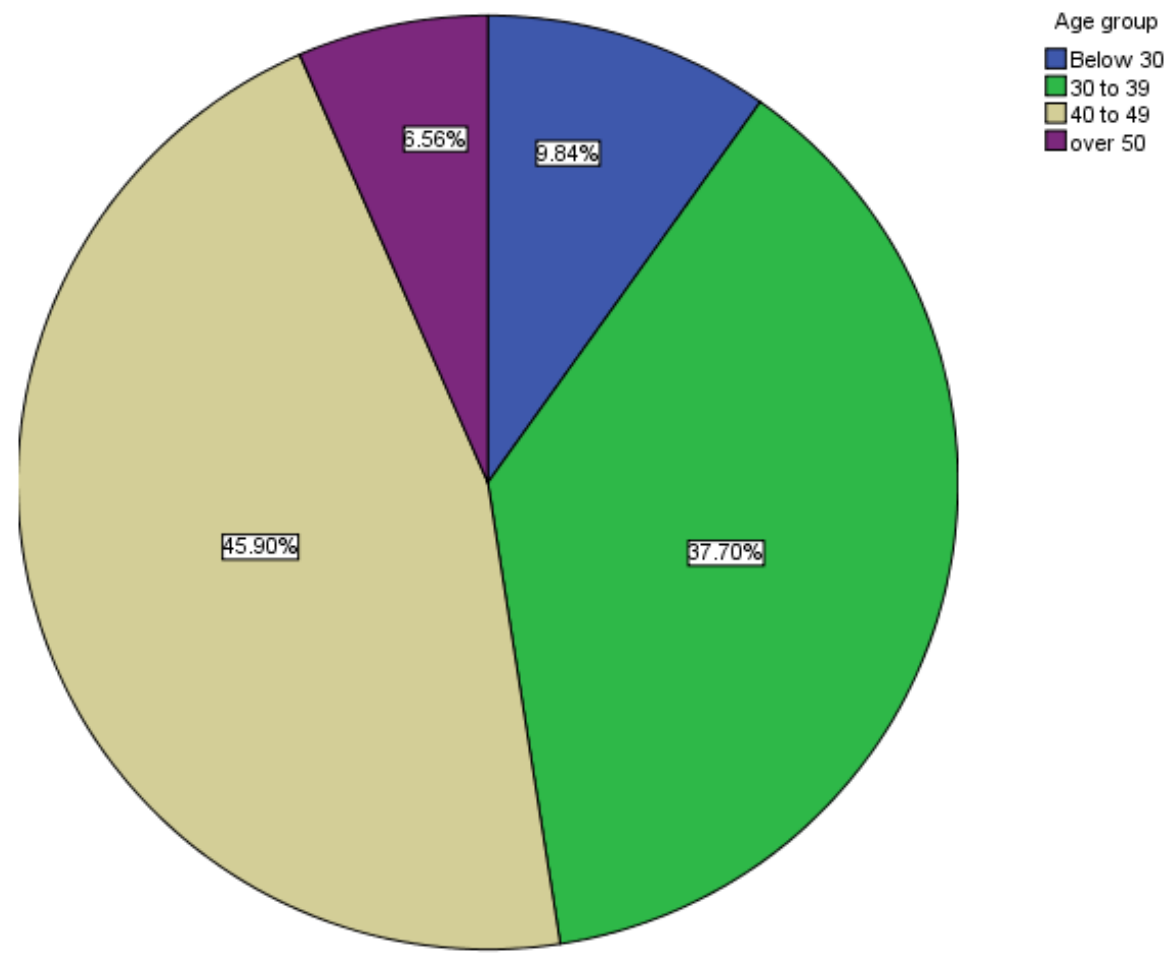

Figure 1. Age-groups composition of the respondents

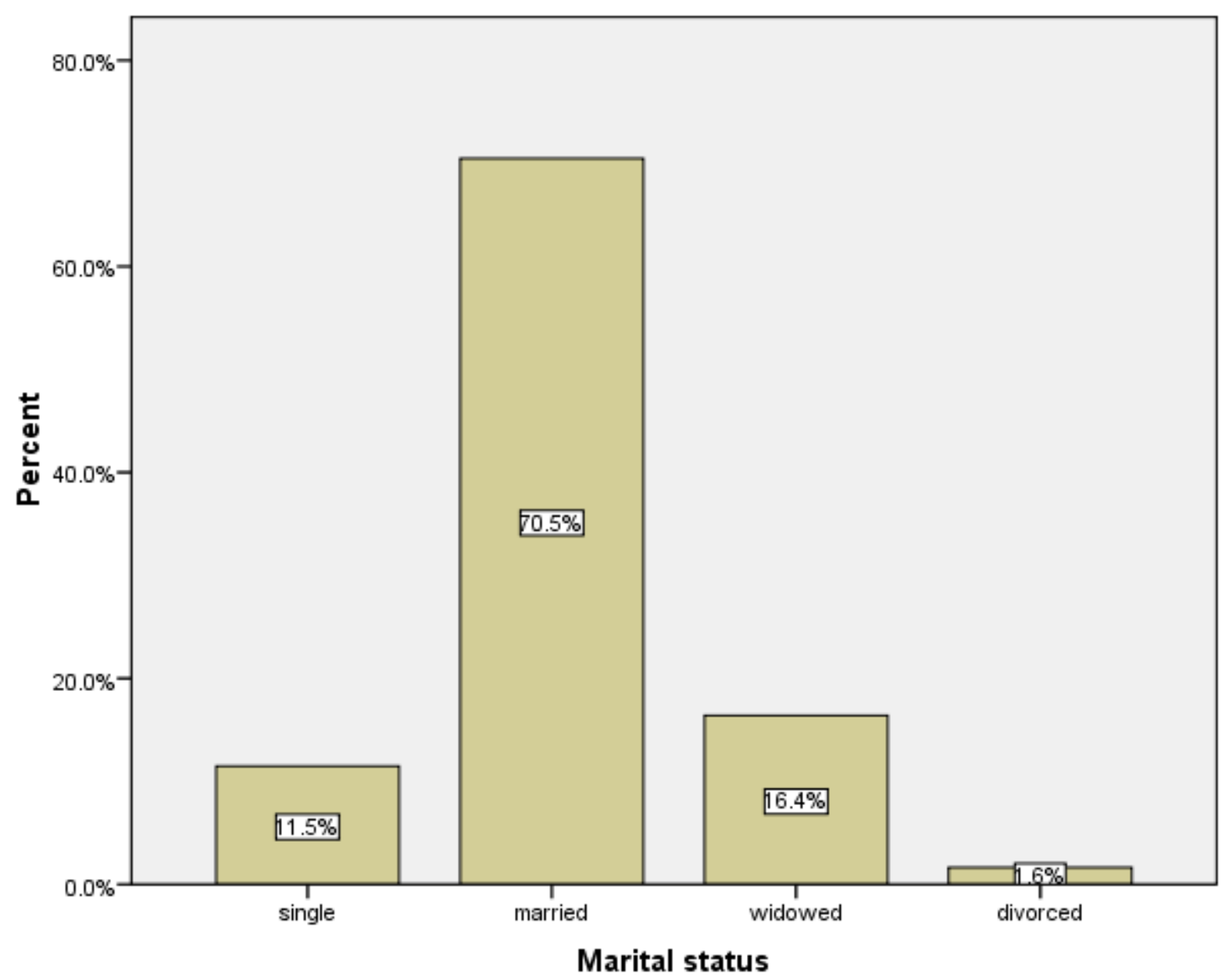

Figure 2. Marital status of the respondents 
Figure 2 shows that $70.5 \%$ of the respondents were married and only $11.5 \%$ of them were single. The distribution of the respondents by religion showed that 48 (78.7\%) were Christians, and 13 (21.3\%) were traditionalists.
Figure 3 shows that $29.51 \%$ of the respondents resided in high density urban (low income) places, and also that $22.96 \%$ of them resided in either rural or peri-urban areas.

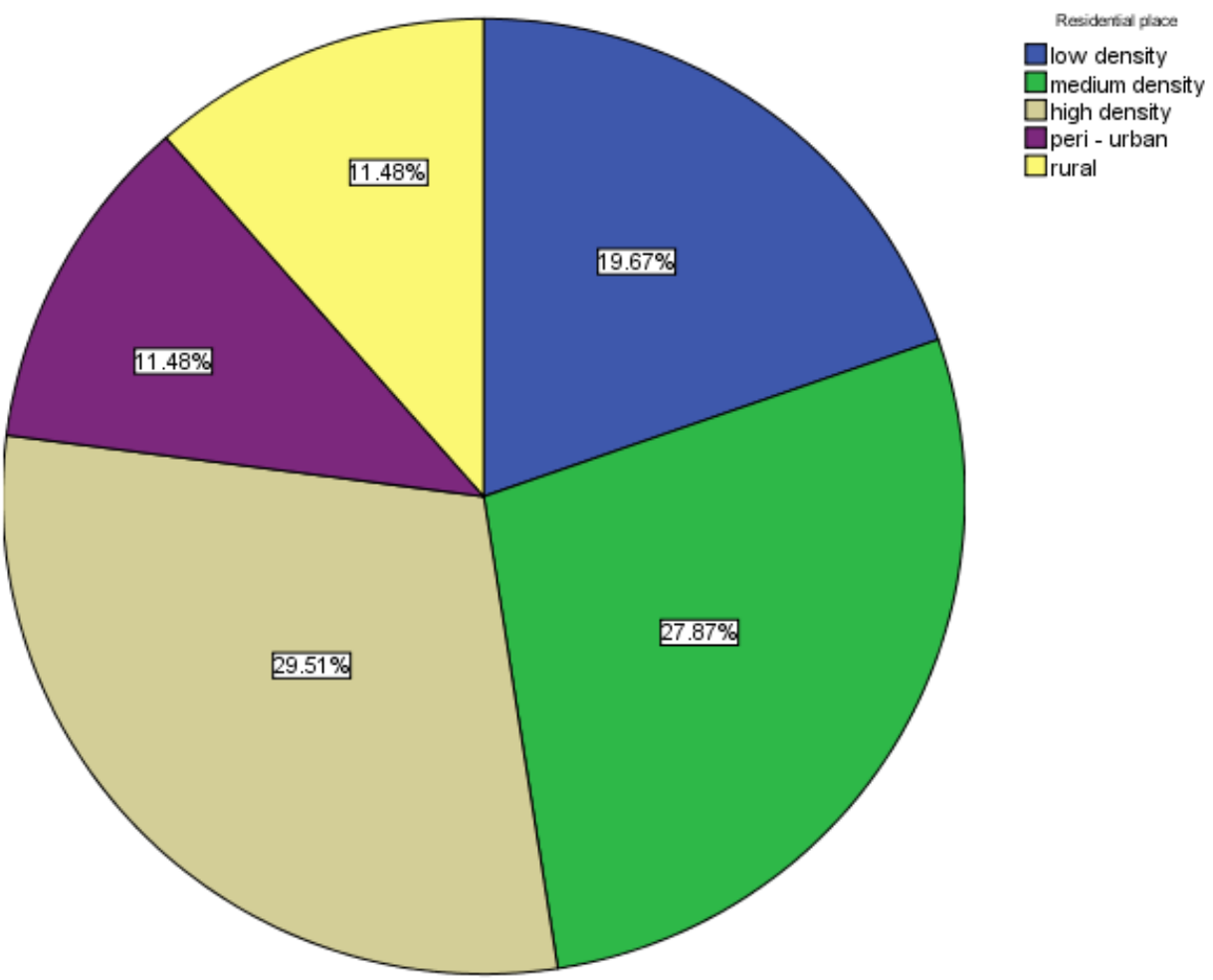

Figure 3. Bar chart of the distribution of the respondents' residential places

The data was captured and analyzed using Statistical and Presentation System Software (SPSS) version 16. Factor analysis with the varimax factor rotation option was applied to determine the factors underlying the perceptions of the prospective teachers on both housemaids and nurseries on ECD. Principal component analysis (PCA) was used to extract the factors as linear combinations of the variables under investigation.

\section{Results and Discussion}

Two ECD functionaries, nurseries and housemaids were investigated based on the perceptions of the student teachers and the following results were obtained.

The KMO measure of sampling adequacy for nurseries was 0.473 showing that about $47.3 \%$ of the variance in the variables would be attributed to the underlying factors, showing that the results of the factor analysis would not be very useful. However, the Bartlett's test of sphericity gave a p-value of less than 0.001 indicating that a factor analysis would be useful on this data. The communalities output showed that the factors explained at least $58.8 \%$ and at most $80.8 \%$ of the variance in the variables under investigation. Six factors were extracted using the PCA method which accounted for $71.29 \%$ of the total variance. The first factor explained $16.51 \%$ of the variance consisted of the perceptions on child's intellectual ability enhancement, social and general awareness, development through peer interactions, and the all-round development of the children being effected by nurseries. The second factor explained $16.10 \%$ of the variance consisted of the perceptions on the child's discipline, learning habits especially on health matters, the child's development of sense of cooperation and team spirit, and the development of the cognitive ability of the child. The third factor explained $11.43 \%$ of the variance and was constituted of the perceptions on personality, use of foreign language, self-reliance, and the communal support intervention for mothers. The fourth factor accounted for $11.02 \%$ of the variance and was composed of the perceptions on the development of the motor skills, the nursery syllabus was not a constraint on the natural development of the child, and that nursery placement hinged on the parents' prestige. The fifth factor explained $8.21 \%$ of the variance and consisted of the perceptions on limitation of space requirements for the optimum growth and development of the child at nurseries. The sixth factor accounted for $8.01 \%$ of the variance and was constituted by the perceptions on nursery being a play, activity and instruction based programme and that nurseries did not provide child care necessarily for time-poor parents.

In the investigation of perceptions on housemaids in ECD by the prospective ECD teachers, the KMO value of 0.712 was obtained showing that factor analysis could well be used on the data. Furthermore the Bartlett's test for sphericity gave a p-value of less than 0.001 further supporting that factor analysis would be useful on the data. The communalities ranged from $57.8 \%$ to $84.6 \%$ showing that the variables were being significantly explained by 
the extracted factors. Five factors were extracted and these explained $71.36 \%$ of the variance in the perceptions gleaned from the respondents. The first factor explained $28.07 \%$ of the variance and was constituted of the student teachers' perceptions on housemaids' help on the development of the children's motor and cognitive skills, being complimentary to nurseries, promotion of children's social and general awareness, stimulate the all-round development of the children, ensuring that children learn good habits, help children develop a sense of cooperation and team spirit, and that they frequently interact with parents on children matters. The second factor accounted for $14.32 \%$ of the variance explained and consisted of the prospective teachers' perceptions on housemaids ensuring child development in a home environment, their allowing the natural development of the children, and their nonlimitation of the space requirements for a child's growth and development. The third factor explained $10.72 \%$ of the variance and was composed of the perceptions on housemaids being a private intervention for mothers, their provision of child-care for time-poor parents, their instilling independence through ensuring that the children did play and activity on their own. The fourth factor accounted for $9.46 \%$ of the variance and was constituted of the perceptions on personality and discipline of the child, and that the needs of children were at the core of the decision to hire housemaids. The fifth factor explained $8.79 \%$ of the variance and consisted of the perception that housemaids promoted the use of the mother language by children.

\section{Conclusions and Recommendations}

The research showed that the perceptions of the prospective teachers on the two important functionaries in ECD, notably nurseries and housemaids can be summarized into six and five, respectively, factors.

The six factors derived from this investigation on the perceptions of the student ECD teachers on nurseries role on ECD can be summarized generally as the all-round development of the child, the intellectual development, personality development, status maintenance and intrinsic motor skills development, space requirements for development, and play-focus and relevance of nurseries, respectively.

The five factors on the perceptions of the prospective ECD teachers on housemaids' impact on ECD can be summarized as the first factor being that the housemaids ensure the intellectual and social ability of children, the second factor being that the housemaids maintaining a homely environment for child growth and development, and the third factor as being that the housemaids are filling the child-rearing gap created by gainfully employed mothers. The fourth factor can be summarized as housemaids influencing the character-mold of the children under their supervision and the fifth factor reveals that housemaids ensuring that children are instilled with the native language of the parents and to some extent cultural values.

It was observed that almost all of the factors gleaned from the perceptions on housemaids revealed that housemaids were complimentary to nurseries on ECD though with an emphasis on home-based grooming of children. The striking factor was of housemaids filling the gap for time-poor parents who were not revealed in terms of nurseries, this can be attributed to the difference in their financial demands and also that housemaids could be hired not necessarily on a long term unlike the requirements of nurseries which can be at least on a one month contract. The other outstanding factor was on the space requirements wherein housemaids had no problems yet limitations were highlighted in regards to nurseries.

We recommend that further research be carried out based on these factors in assessing the influence of the demographic factors of the respondents on them in terms of associations based on either chi-square or ANOVA tests. The scope of this research could be further extended to ascertain the opinions of either ECD teachers and housemaids or the parents of the children on these factors in regards to profound ECD dynamics in view of the empowerment initiatives for women and the universal access to primary education, i.e. the attainment of the millennium development goals (MDG), 2 and 3, respectively. The language emphasis gap between housemaids and nurseries would be of great interest in the future to explore in the wake of the acceptance of a plethora of languages in the new Zimbabwean constitution as official for these may have an impact on the educational curriculum requirements in as early as ECD. The complimentary effect to nurseries in the main factor for housemaids also suggests the need for association investigation on these functionaries in ECD.

We also recommend that for a considerable high sample size, further research be conducted through the application of either structural equation models or regression methods such as random effects models or logistic models to allow for interaction effects and hence aid clarity of interpretation of the data.

\section{Statement of Competing Interests}

The authors have no competing interests.

\section{List of Abbreviations}

$\begin{array}{ll}\text { ANOVA } & \text { Analysis of variance } \\ \text { ECD } & \text { Early Childhood Development } \\ \text { MDG } & \text { Millennium Development Goal } \\ \text { PCA } & \text { Principal Component Analysis } \\ \text { WUA } & \text { Women's University in Africa }\end{array}$

\section{References}

[1] Bennett, J., and Coram, T. (2009) Early Childhood Education Services in Dubai, Knowledge and Human Development Authority, Dubai, December 2009.

[2] Pound, L. (2005) How Children Learn: From Montessori to Vygotsky- Educational Theories and Approaches made easy, Routledge, London.

[3] Demma, R. (2005) Building an Early Childhood Professional Development System, Routledge, London.

[4] Haney, M. and Bissonnette (2011) Teachers' Perceptions about the Use of Play to Facilitate Development and Teach Prosocial Skills. Creative Education 2011. Vol. 2, No. 1, 41-46.

[5] Lindsey, E.W. and Colwell, M/.J, (2003) Preschoolers' emotional competency: Links to pretend and physical play. Child Study Journal 33, 39-52. 
[6] Frost, J.L., Wortham, S.C. and Reifel, S.(2001) Play and Child Development . Prentice Hall. New Jersey.

[7] Fisher, K. R., Hirsh- Pasek, K., Golinkoff, R. M. and Gryfe, S.G. (2008) Conceptual Split? Parents' and experts' perceptions of play in the $21^{\text {st }}$ century. Journal of Applied Developmental Psychology 29(2008) 305-316.

[8] Ginsburg, H. P., Cannon, J., Eisenband, J. G. and Pappas, S. (2005) Mathematical thinking and learning. Journal of Applied Developmental Psychology 29 (2008) 305-316.

[9] Berk, L.E., Mann, T. D. and Organ, A. T. (2006) Make - believe play; Wellspring for development of self - regulation. Journal of Applied Developmental Psychology 29(2008) 305-316.

[10] Tassoni, P. and Hucker, K. (2005) Planning Play and the Early Years (Second Edition) Heinemann Essex.

[11] Tamang, (2002) Education in Mother Tongue in Nepal. Tribhuvan University Kathmandu.
[12] Zimbabwe Education Act 1996 Revised Edition Ministry of Education, Sport, Arts and Culture, Harare.

[13] Roumani, H.B, "Maids in Arabia: the Impacts of maids as Careers on Children's Social and Emotional Development," Journal of Early Childhood Research, 3(2). 149-167. June 2005.

[14] Goh, E, (2006) Raising the precious single child in urban ChinaAn intergenerational joint mission between parents and grandparents. Journal of Intergenerational Relationships, 4.7-28.

[15] Ministry of Education, Sport, Arts and Culture (2005) Statutory Instrument 106 of 2005.Government Printers, Harare.

[16] Matangi, E. S., Kashora, P., Mhlanga, A., \& Musiyiwa, J. (2013). Perceptions on the Interplay of Housemaids and Nurseries on Early Child Development (Ecd). American Journal of Educational Research, 1(6), 194-198. 